\title{
UNA EMPRESA PÚBLICA EXCEPCIONAL EN UNA SOCIALDEMOCRACIA EN CRISIS: EL INSTITUTO COSTARRICENSE DE ELECTRICIDAD
}

\author{
Daniel Chavez \\ Transnational Institute, Holanda \\ chavez@tni.org \\ Alberto Cortés Ramos \\ Universidad de Costa Rica, Costa Rica \\ acortes.ramos@gmail.com
}

\section{RESUMEN}

El artículo presenta un análisis de la economía política de la energía en Costa Rica y del lugar especial que el Instituto Costarricense de Electricidad (ICE), la empresa responsable de la provisión de servicios de energía y telecomunicaciones, ha ocupado históricamente en la configuración de la identidad nacional. El supuesto básico es que el perfil institucional del ICE, su evolución y sus impactos sobre el desarrollo han sido moldeados por condiciones políticas, sociales y económicas muy específicas y difíciles de replicar en otros países del Sur. En específico, se argumenta que, desde su fundación en el año 1949, el ICE se ha convertido en uno de los pilares de un peculiar Estado de bienestar y de un modelo solidario de desarrollo que figura entre los más avanzados del mundo en términos de progreso social.

Palabras clave: Empresas públicas, Economía política, Reformas, Costa Rica. 


\title{
AN EXCEPTIONAL PUBLIC COMPANY WITHIN A SOCIAL DEMOCRACY IN CRISIS: THE COSTA RICAN INSTITUTE OF ELECTRICITY
}

\begin{abstract}
The article presents an analysis of the economic policy of energy in Costa Rica and of the exceptional role which the Costa Rican Institute of Electricity (ICE) - the company responsible for the provision of energy and telecommunications - has historically held in shaping the national identity. The basic assumption is that the institutional profile of the ICE, as well as its evolution and impact on development have been shaped by very specific political, social and economic conditions which are difficult to replicate in other developing countries in the South. It is specifically argued that, since its foundation in 1949, ICE has become one of the cornerstones of a peculiar kind of welfare state and of a solidarity model for development which is listed among the most advanced in the world in terms of social progress.
\end{abstract}

Keywords: Public companies, Economic policy, Reforms, Costa Rica. 


\section{INTRODUCCIÓN}

Costa Rica es un ejemplo sobresaliente de suministro eficiente e igualitario de servicios públicos. El país ha asegurado el acceso a la electricidad, el agua, la salud y la educación a todos los sectores sociales y todas las regiones del país, con indicadores notables de equidad, calidad, asequibilidad, ética pública y sostenibilidad ambiental. Desde su fundación en el año 1949, el Instituto Costarricense de Electricidad (ICE), la empresa responsable de la provisión de servicios de energía y telecomunicaciones, se ha convertido en uno de los pilares de un peculiar Estado de bienestar y de un modelo solidario de desarrollo que figura entre los más avanzados del mundo en términos de progreso social.

Nuestra investigación se centró en el análisis de la economía política de la energía en Costa Rica y del lugar especial que el ICE ha ocupado históricamente en la configuración de la identidad nacional. El supuesto básico es que el perfil institucional del ICE, su evolución y sus impactos sobre el desarrollo han sido moldeados por condiciones políticas, sociales y económicas muy específicas y difíciles de replicar en otros países del Sur. La ciudadanía costarricenses es consciente de la significación del Estado en la economía y en la sociedad y ha resistido diversos intentos de privatización de las empresas públicas. El ICE, en particular, es percibido como un motor esencial del desarrollo y ha estado en el centro de las movilizaciones sociales más importantes de las últimas décadas.

\section{EL CONTEXTO NACIONAL}

Los investigadores académicos y los teóricos del desarrollo a menudo se refieren a Costa Rica como un país modelo. Servicios básicos como el agua, la salud y la educación son accesibles para todos los sectores de la población y el índice nacional de esperanza de vida, 79,3 años al nacer, el más alto en América Latina, ubica a Costa Rica por encima de Estados Unidos y de países europeos como Dinamarca, Eslovaquia, República Checa, Hungría y Polonia. El relativamente modesto producto interno bruto (PIB) nacional, alrededor de US\$ 10.500 en paridad de poder adquisitivo per cápita, hace que su alto nivel de desarrollo social sea aun más notable (PNUD 2011).

Las raíces del Estado de bienestar en Costa Rica se establecieron con las reformas sociales de inicios de la década de 1940 y se ampliaron a partir de 1948, después de una fugaz guerra civil que concluyó con un pacto consensuado entre las principales fuerzas políticas del país. El sendero socialdemócrata que el país recorrió en el período posterior fue influenciado por el paradigma desarrollista prescrito por la Comisión Económica para América Latina y el Caribe (CEPAL), que proponía una fuerte intervención 
estatal en la economía, la promoción de la industrialización por sustitución de importaciones (ISI), la implementación de políticas sociales integrales de cobertura universal y una moderada reforma agraria (Bulmer-Thomas 1987, Wilson 1998). A pesar de su relativo éxito, el modelo socialdemócrata ha sido crecientemente cuestionado por los propulsores del neoliberalismo en el gobierno desde hace tres décadas (Wilson 1994, Seligson 2002, Haglund 2011).

Entre las décadas de 1950 y 1980 , y en particular durante el clímax del período de Estado empresario (véase Sojo 1984), el aparato estatal se convirtió en el elemento catalizador de la economía de Costa Rica. El Estado operaba empresas en una amplia variedad de sectores, que iban desde la producción de aluminio y azúcar hasta la energía y las telecomunicaciones, los servicios financieros y los seguros, los servicios de agua y las refinerías de petróleo (Mas Rovira 1989).

En ese contexto, el ICE adquirió un rol sustancial (Bull 2008), pasando a ser la empresa estatal responsable de la generación y el suministro de energía eléctrica y también del sistema nacional de telecomunicaciones, dando lugar a una empresa casi única a nivel internacional. El ICE ha proporcionado la energía requerida para ejecutar los planes de desarrollo y de industrialización que el Estado impulsó desde la década de 1950 y ha asumido una función social fundamental, invirtiendo cuantiosos recursos para consolidar un sistema nacional de suministro eléctrico desde una perspectiva de inclusión y de equidad. Como ya ha sido destacado por investigaciones previas "el ICE se convirtió en probablemente la institución más emblemática del modelo de desarrollo costarricense" (Hoffmann 2007: 11).

\section{COSTA RICA: UNA EXTRAÑA SOCIALDEMOCRACIA TROPICAL}

Al igual que lo acontecido en otros países de América Latina, la inserción de Costa Rica en el mercado mundial se basó originalmente en la producción de materias primas agrícolas. En la década de 1920, Costa Rica se caracterizaba por un magro crecimiento económico, una legislación laboral limitada, un mercado interno reducido, una débil industrialización y un sector agrícola estructurado en torno a cultivos de exportación, básicamente café y bananas (Bulmer-Thomas 1987). Fue bajo estas circunstancias como se produjo la reorientación inicial del sector eléctrico nacional.

A lo largo de los años 1930 y 1940, el activismo social en ascenso obligó al Estado a adoptar un papel más activo en la economía y mediar en las relación capital-trabajo, lo que tornó más difícil para la clase capitalista agraria definir la agenda política. El Partido Comunista de Costa Rica 
(PC), fundado en 1931, "logró la unificación exitosa de segmentos urbanos y rurales étnicamente diversos, trabajadores del campo y obreros fabriles, aportando nuevas habilidades organizativas a los campesinos sin tierra" (Shin y Hytrek 2002: 470). Al mismo tiempo, otras fuerzas sociales -el clero, intelectuales liberales, trabajadores de cuello blanco, pequeños empresarios rurales y urbanos, entre otros- temerosas del fortalecimiento del PC promovieron la creación de nuevas organizaciones políticas y cívicas, como el Partido Social Demócrata (PSD) y la Confederación Costarricense de Trabajadores Rerum Novarum (CCTRN).

En 1940, Rafael Calderón Guardia, un político partidario de la doctrina social de la Iglesia Católica apoyado inicialmente por la oligarquía cafetalera, fue elegido presidente con un masivo apoyo electoral: $85 \%$ (Bull 2008). Las reformas sociales que impulsó inicialmente, que incluyeron la Ley de Seguridad Social, la creación de la Caja Costarricense de Seguridad Social y la Universidad de Costa Rica, le distanciaron y enfrentaron con la oligarquía. En 1943, Calderón Guardia estableció una heterodoxa alianza con el Partido Comunista, liderado por Manuel Mora, y la jerarquía de la Iglesia Católica, encabezada por Monseñor Víctor Sanabria, posibilitando la aprobación de otras reformas sociales, incluyendo el Código del Trabajo. El Presidente alcanzó un amplio apoyo entre los pobres, pero una coalición formada por terratenientes del campo, industriales, oficiales militares conservadores y los sectores más tradicionalistas de la iglesia se opuso firmemente a sus políticas reformistas.

El candidato de su partido, Teodoro Picado, ganó las elecciones de 1944 de forma más ajustada. Tras un lapso de cuatro años, en 1948, Calderón Guardia se postuló nuevamente y fue derrotado. El candidato conservador, Otilio Ulate, triunfó por un estrecho margen y fue proclamado presidente por la Junta Electoral. El Parlamento anuló el resultado y Calderón Guardia asumió el poder, pero poco después tuvo que enfrentar una insurrección liderada por José Pepe Figueres -un cultivador de café y líder del PSDapoyada inicialmente por la oligarquía, que derrotó a las fuerzas progubernamentales.

El muy peculiar proceso político ulterior arraigó la socialdemocracia en Costa Rica de una manera difícilmente replicable en otros países. Después de un breve estallido de violencia, que causó entre 1.000 y 1.300 muertos (Bull 2008), la guerra civil concluyó con impactos significativos en términos de cambio institucional y social. En un período de menos de dos ańos, bajo el liderazgo de Figueres, la Junta Revolucionaria y la Asamblea Constituyente aprobaron varias leyes que dieron forma a la evolución política y económica del país en el resto del siglo, incluyendo la nacionalización de la banca privada, la consolidación y ampliación de la legislación social y laboral 
aprobada en años anteriores, la abolición del ejército, y la creación del ICE. Tales acciones afectaron los intereses de las fracciones más tradicionales de la burguesía agraria y beneficiaron a las fracciones más modernas del capital vinculadas al sector industrial emergente, los pequeños y medianos productores agrícolas y los trabajadores del sector público. Los cimientos del proceso que ha sido caracterizado como la vía costarricense (véase Vargas 2005) habían sido establecidos.

Las secuelas de la revolución de 1948 se tornaron más visibles en varias dimensiones del orden político y social en los años posteriores. El movimiento sindical se debilitó y se dividió y el poder de las elites conservadoras se redujo en el período de postguerra. Con el retorno a la democracia en el ańo 1950 y la legislación social consolidada en el entramado constitucional (por ejemplo, en las previsiones legales en torno a la seguridad social, el código laboral y la legislación impositiva) se instituyó la base institucional del régimen socialdemócrata post-1950 (Shin y Hytrek 2002).

En 1951 Figueres fundó el Partido Liberación Nacional (PLN), con el que ganó de forma contundente las elecciones de 1953. Este partido tuvo una clara hegemonía en la política costarricense hasta el año 1978. Con Figueres otra vez como presidente entre 1970 y 1974, el papel del Estado se amplió aún más con la creación de la Corporación Costarricense de Desarrollo (CODESA), un inmenso holding industrial de propiedad 67\% estatal que se consolidó en el gobierno del también liberacionista, Daniel Oduber en los años 1974-1978 (Jiménez Gómez 2009).

Durante la mayor parte del período de posguerra la sociedad costarricense se benefició de un período de crecimiento económico prolongado y de políticas sociales de avanzada. No obstante, en el contexto de la recesión mundial de la década de 1980 y el agotamiento de la estrategia ISI, frente a condiciones desfavorables en los mercados financieros globales, crecientes necesidades energéticas, una caída en el precio internacional del café y problemas relacionados al acceso a divisas, las élites económicas y políticas comenzaron a presionar por un cambio radical en la política económica. Los gobiernos de la década de 1980 y 1990 introdujeron nuevas medidas orientadas al mercado, que incluyeron recortes en el gasto público, la venta de empresas del grupo CODESA, la liberalización del comercio en conformidad con el Acuerdo General sobre Aranceles Aduaneros y Comercio (GATT) y la eliminación de subsidios a productos agrícolas para el consumo interno.

Sin embargo, las políticas neoliberales aplicadas en Costa Rica fueron más graduales y menos brutales que en otros países de América Latina 
(Mesa-Lago 2003), en parte debido a las características peculiares de un sistema institucional basado históricamente en la negociación y la búsqueda de consensos entre diferentes fuerzas políticas y sociales, y en parte debido a la especial importancia que Costa Rica llegó a tener como un ejemplo que las organizaciones internacionales hegemónicas podían exhibir como una alternativa a los proyectos revolucionarios de izquierda surgidos en otros países de América Central ${ }^{1}$.

\section{La EVOLUCión de los SERVICIOS DE ELECTRICIDAD EN Costa RiCa}

La historia de la electricidad en Costa Rica se inició en 1884, cuando se instaló el primer generador. La planta, con una capacidad de unos $50 \mathrm{Kw}$, proveía la energía necesaria para el alumbrado público en la ciudad capital, San José, y cubría las necesidades particulares de unas pocas familias de altos ingresos (Jiménez Gómez 2009).

A mediados de 1920, el sector privado ya no era capaz de hacer frente a la progresiva demanda de energía. La capacidad total instalada en 1927 ascendía a $10.820 \mathrm{Kw}$. En 1928, las tres empresas proveedoras existentes fueron adquiridas por la American and Foreign Power, la filial local de la firma estadounidense Electric Bond and Share Company (EBASCO), dando lugar a la creación de la Compañía Nacional de Fuerza y Luz (CNFL). El control del mercado por una sola empresa, la limitada cobertura de la red (un puñado de ciudades y pueblos en el Valle Central) y la baja calidad de los servicios generó un descontento generalizado (Rodríguez Argüello 2000).

Entre 1928 y 1929, el Parlamento aprobó una ley que nacionalizó la energía que se produciría utilizando los recursos hídricos bajo dominio público y creó una nueva agencia estatal responsable de la regulación y la eventual generación energética: el Servicio Nacional de Electricidad (SNE). En los años siguientes, la demanda continuó creciendo, pero los operadores privados no invirtieron en el mantenimiento y la ampliación de los servicios (Fernández Robles 1985 Rodríguez Argüello 2000). En la década de 1940 la situación ya era crítica.

I Los intereses geopolíticos estadounidenses en la región centroamericana y caribeña constituyen otra variable que debe ser considerada al evaluar las características particulares del país. Si bien esta variable no explica la expansión del sector público costarricense durante la Guerra Fría, el hecho de que el bloque político triunfador de la guerra civil (I948) asumiera una clara posición anticomunista amplió el margen de maniobra político, económico y social del gobierno nacional, habilitando así las políticas reformistas que permitirían la consolidación del Estado de Bienestar o solidario costarricense. En la década de I980, en particular, Costa Rica funcionó como país vitrina frente al proceso revolucionario nicaragüense liderado por los Sandinistas (Grosfoguel 2003). 
En el año 1949 se aprobó la creación del ICE. El instituto fue puesto a cargo de la provisión de la energía necesaria para la expansión y la modernización de los sectores agrícola e industrial y de la provisión de servicios de electricidad asequibles (Fallas y Álvarez 1997). El primer artículo del Decreto Ley N. ${ }^{\circ 449}$ establecía lo siguiente:

Créase el Instituto Costarricense de Electricidad, en adelante llamado el Instituto, al cual se encomienda el desarrollo racional de las fuentes productoras de energía física que la Nación posee, en especial los recursos hidráulicos. La responsabilidad fundamental del Instituto ante los costarricenses será encauzar el aprovechamiento de la energía hidroeléctrica con el fin de fortalecer la economía nacional y promover el mayor bienestar del pueblo de Costa Rica.

El segundo artículo detallaba los objetivos del instituto, incluyendo:

Procurar la utilización racional de los recursos naturales y terminar con la explotación destructiva y desperdiciada de los mismos [y] conservar y defender los recursos hidráulicos del país, protegiendo las cuencas, las fuentes y los cauces de los ríos y corrientes de agua (Junta Fundadora de la Segunda República 1949: 1)².

En 1952, el Plan Nacional de Electrificación propuso como meta la cobertura total del servicios en el Valle Central, donde residía el 65\% de la población del país. El ICE también pasó a ser responsable de extender los servicios a localidades donde el abastecimiento de electricidad estaba en manos de gobiernos municipales. Según las estadísticas de la época, sólo el $55 \%$ de la población del país estaba por entonces cubierta por la red (Jiménez Gómez 2009).

En un primer momento, el ICE se dedicó a fortalecer los servicios existentes, para luego invertir de forma constante en la expansión. En las décadas de 1960 y 1970, en particular, el Estado construyó grandes proyectos hidroeléctricos -La Garita, 1958; Río Macho, 1963; Cachí, 1966; Tapantí, 1972- y amplió la red nacional hasta cubrir prácticamente la totalidad del territorio nacional. A medida que la empresa pública se expandía, las empresas privadas y extranjeras abandonaban el mercado de Costa Rica, tomando el ICE el control de la CNFL como empresa subsidiaria. Por otra parte, durante la década de 1960, bajo la influencia del

2 La Asamblea Constituyente de 1949 promovió la creación de diversos institutos autónomos como entidades estatales descentralizadas del Poder Ejecutivo y con capacidad de autogobierno, incluyendo tanto a empresas del Estado como a otras instancias en diversas áreas de la gestión pública. 
movimiento asociativo en Estados Unidos, se consolidaron las cooperativas de electrificación rural, las que durante muchos ańos contaron con el apoyo del ICE para ampliar la cobertura de la red.

\section{LOS RESULTADOS DEL ICE}

El instituto cuenta con una larga tradición de planificación eficiente y de operación de servicios basada en una muy alta capacidad técnica y administrativa, y expresiva de un sentido de lo público vibrante. En las páginas siguientes se intentará demostrar, a partir del análisis del desempeño pasado del ICE y los actuales indicadores de gestión, que incluso los argumentos supuestamente progresistas, esgrimidos por los reformadores neoliberales para reclamar una mayor liberalización del sector (tales como la profundización de la seguridad energética en base a fuentes renovables), no tienen cabida, ya que las metas propuestas ya han sido alcanzadas.

\section{COBERTURA Y CALIDAD DE LOS SERVICIOS}

Costa Rica tiene la mejor cobertura de servicios de electricidad de América Latina. Desde su creación, el instituto ha ampliado el acceso del 14\% en 1949 a más del 99\% en la actualidad (SIICE 2011). Entre 1985 y 1999, el sistema eléctrico nacional ha triplicado su capacidad, en línea con el crecimiento del PIB.

El sistema eléctrico nacional está compuesto por el ICE, la Compañía Nacional de Luz y Fuerza (CNFL), dos empresas municipales y cuatro cooperativas de electrificación rural. La CNFL, una empresa pública dedicada a la transmisión y la distribución de energía en San José y en la región metropolitana, está controlada casi en su totalidad por el ICE (96\% de la propiedad). Desde la liberalización del sector eléctrico, en la década de 1990, la CNFL también participa en la generación. En la actualidad, Costa Rica muestra importantes diferencias con los países que han realizado reformas de mercado más radicales en el sector eléctrico, como muestra el Cuadro 1. 


\section{Cuadro 1: La situación del sector eléctrico en países que han adoptado reformas de mercado y en Costa Rica}

\section{Tipo de reforma Países con reformas de mercado}

La propiedad de los activos y las

Privatización responsabilidades de gestión se han transferido desde el Estado al sector privado.

Funciones separadas (generación,

Desestructuración vertical (unbundling)

Mercado mayorista de la energía eléctrica

Regulación

Provisión de servicios y subsidios

Responsabilidad del suministro

Decisiones en el área de generación

Utilización de fuentes renovables de energía transmisión, distribución y venta al por menor) han sido adjudicadas a diferentes empresas o unidades comerciales.

La electricidad ha pasado a ser una vendida y distribuida de acuerdo a las reglas del libre mercado.

Tras la liberalización del sector eléctrico, la regulación está centrada principalmente en el cumplimiento de las reglas del mercado.

Los subsidios se han eliminado o reducido y la cobertura de los servicios de electricidad tiende a priorizar las áreas y sectores sociales más rentables.

La responsabilidad de la prestación de servicios de energía eléctrica se ha diluido entre diferentes entidades públicas y privadas.

Las decisiones referidas a la generación siguen las leyes de la oferta y la demanda en el mercado de la electricidad.

El desarrollo de fuentes renovables en el sector eléctrico se basa en criterios mercado. mercancía que puede ser comprada,

\section{Costa Rica}

El ICE sigue siendo enteramente de propiedad del Estado, pero el gobierno promueva la expansión del sector privado en las áreas de generación y distribución.

El ICE sigue existiendo como una empresa verticalmente integrada, pero compañías privadas activas en la distribución han sido autorizadas a participar en actividades de generación.

No existe un mercado mayorista, pero el Parlamento está considerando diversas iniciativas legislativas hacia una mayor liberalización del sector eléctrico.

El sector eléctrico está legalmente regulado y supervisado por la Autoridad Reguladora de los Servicios Públicos (ARESEP) y el ICE continúa siendo el principal actor en el sector.

El sistema de tarifas del ICE se basa en subsidios cruzados que facilitan el acceso asequible a los servicios de electricidad a todos los sectores de la población.

El ICE continúa siendo la principal entidad responsable del suministro de servicios de electricidad en todo el país.

El ICE es la principal entidad responsable de la generación en respuesta a la demanda nacional de energía eléctrica.

El ICE sigue siendo el principal catalizador del desarrollo de fuentes renovables, sobre la base de la planificación normativa.

Fuente: Adaptado de Jiménez Gómez (2009).

Las dos empresas de propiedad de los gobiernos locales, la Junta Administrativa del Servicio Eléctrico Municipal de Cartago (JASEC) y la Empresa de Servicios Públicos de Heredia (ESPH) se crearon con el objetivo de intervenir en la generación y la distribución de energía eléctrica 
a nivel municipal (Ley N. ${ }^{\circ} 3.300 / 1964$ y Ley N. ${ }^{\circ}$ 5.889/1976). Las cuatro cooperativas -Coopeguanacaste, Coopesantos, Coopelesca y Coopealfaro Ruiz- se fundaron en 1963, con el propósito de distribuir energía eléctrica en comunidades rurales. Las cooperativas han formado un consorcio sin fines de lucro que también participa en la generación.

El sistema costarricense permitió la participación en la generación de energía a empresas comerciales privadas a partir de la década de 1990. Las actividades y las tarifas de los proveedores comerciales son regulados por el ente regulador y también pueden participar en asociaciones públicoprivadas a través de arreglos operativos de tipo BOT (construir-operartransferir).

La entidad jurídica responsable de la regulación de los servicios de electricidad es la Autoridad Reguladora de los Servicios Públicos (ARESEP), creada en 1996 (Ley 7.593) como el organismo que se hizo cargo de las responsabilidades anteriormente en manos del SNE. La ARESEP es responsable de la regulación y la supervisión de los servicios abastecidos por los proveedores públicos y privados, incluyendo la fijación de precios y tarifas y el control de la calidad, la cantidad, la continuidad del suministro, y el otorgamiento de nuevas concesiones para la generación, transmisión o distribución de energía. El ICE es el único comprador en el país y es también propietario de las líneas de transmisión.

El modelo solidario costarricense ha logrado la cobertura más amplia de América Latina (véase el Gráfico 1), al haber invertido en proyectos socialmente rentables pero económicamente no ventajosos, tales como la extensión de servicios a zonas geográficamente alejadas o escasamente pobladas. En el año 2009, el consumo nacional de electricidad ascendió a $8.238 \mathrm{GW}$, de los cuales el ICE proporcionó el 40\%; la CNFL aportó otro $40 \%$ y las cooperativas y empresas municipales el restante $20 \%$. En términos de cobertura geográfica, el ICE es responsable de la provisión de electricidad en la mayor parte (78\%) del territorio nacional (SIICE 2011). 
Gráfico 1: Porcentaje de acceso a servicios de electricidad en América Latina y el Caribe (ańo 2009)

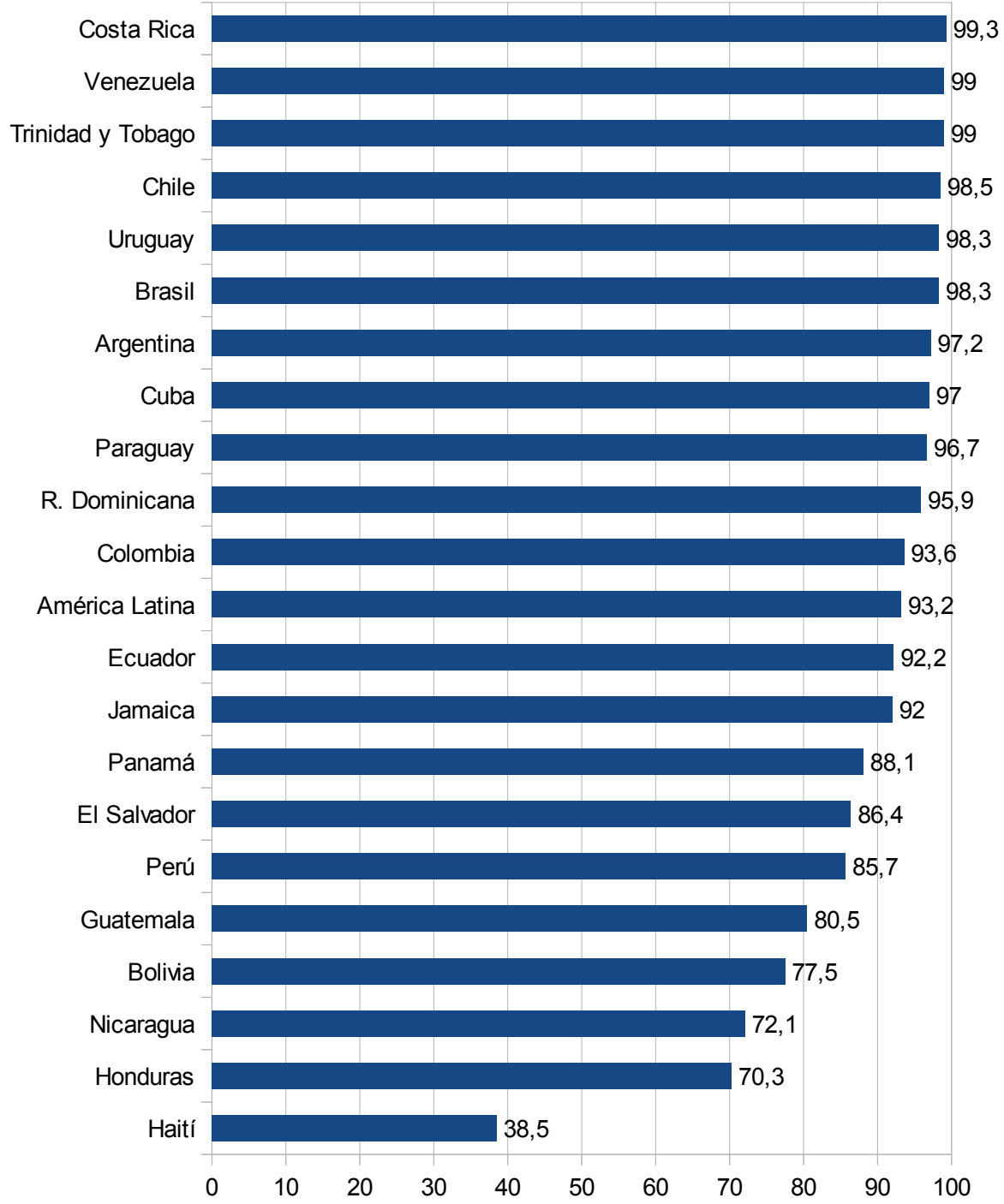

Fuente: IEA (2011).

En lo concerniente a capacidad de generación instalada, el papel del ICE es aún más significativo. En la actualidad, la capacidad nacional de generación asciende a 2.500 MW, de los cuales el ICE controla el 81\% (4\% en manos de la CNFL). Al mismo tiempo, más de la mitad de los alrededor de 40.000 kilómetros de líneas de alta tensión han sido construidas por el 
instituto.

Con referencia al costo de los servicios, el precio de la electricidad en Costa Rica sigue siendo más barato que en la mayoría de los países latinoamericanos, como lo muestra el Gráfico 2. Según los cálculos del ICE, utilizando como indicador el porcentaje del salario mínimo mensual que debe destinarse a pagar por un consumo residencial de $250 \mathrm{kWh}$, sólo tres países de la región -Venezuela, Argentina y Paraguay, donde el costo de la electricidad ha estado congelado desde el año 2002- tienen precios más bajos. En Costa Rica, 250 kWh serían suficientes para satisfacer las necesidades mensuales de los hogares de bajos y medianos ingresos. El consumo promedio nacional en 2009 fue ligeramente superior a $224 \mathrm{kWh}$, y el $75 \%$ de los usuarios del ICE consumieron esa cantidad de energía o menos. En promedio, en otros países de América Latina, los usuarios tienen que dedicar el 14,6\% del salario mínimo a pagar una cantidad equivalente de electricidad, mientras que en Costa Rica es necesario destinar sólo el 7\% de la misma unidad de ingresos (CENPE 2009). 


\section{Gráfico 2. Precio promedio de la electricidad en América Latina y el Caribe (consumo residencial, US\$ cent/kWh; año 2009)}

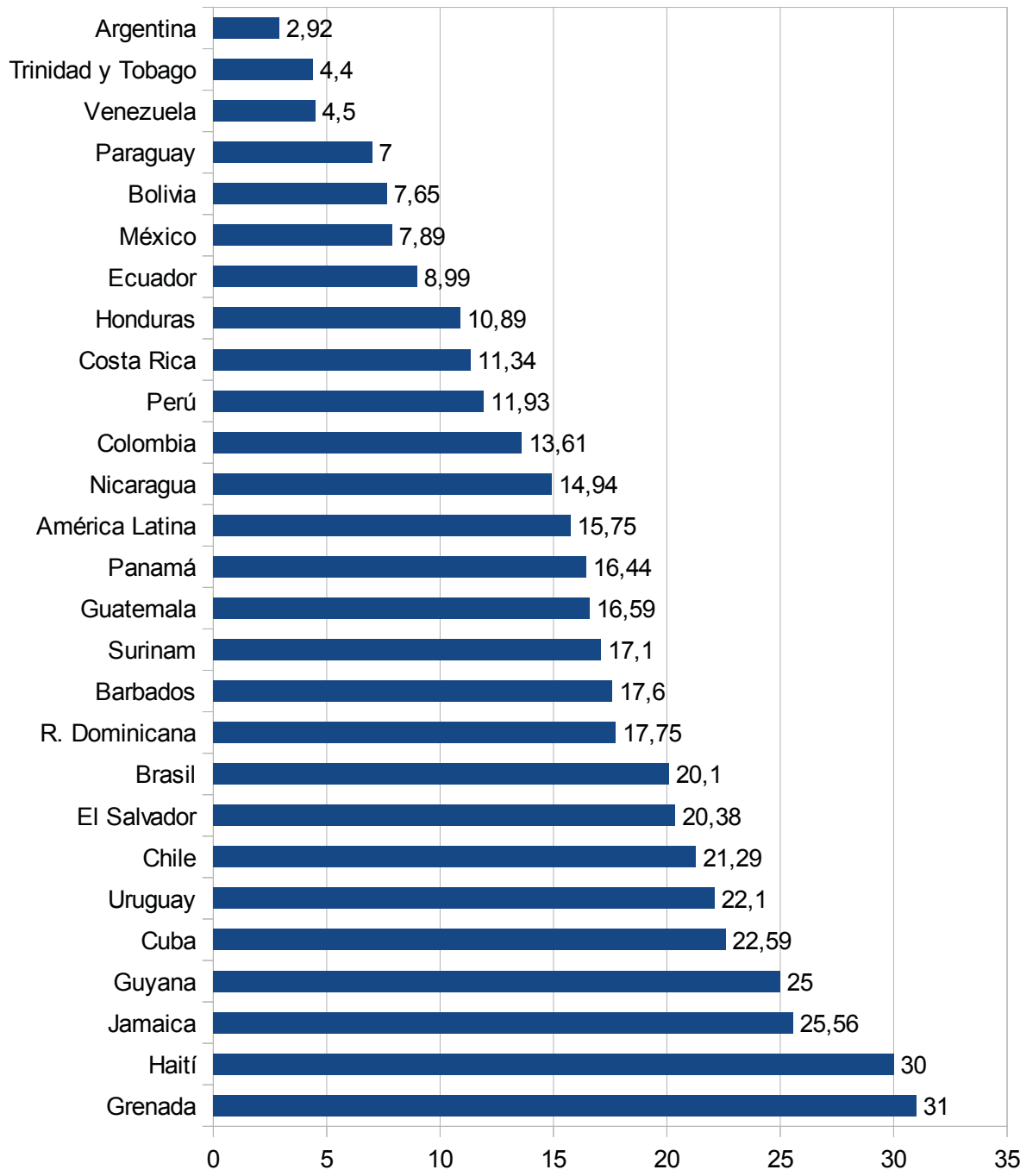

Fuente: OLADE (2010).

En cuanto a la calidad de los servicios, la inversión del instituto en la expansión y el mantenimiento de la red nacional se ha traducido en el sistema de electricidad más eficiente de América Latina. Según el sindicato de ingenieros,

[...] la población costarricense, acostumbrada a un buen servicio eléctrico, es mucho más exigente, pues se considera que este servicio es un derecho fundamental al cual deben tener acceso todos los 
habitantes, independientemente de la ubicación geográfica, posición social o capacidad económica de los usuarios (SIICE 2011: 19).

En cuanto a la seguridad del abastecimiento, durante las últimas tres décadas Costa Rica sufrió sólo un período de racionamiento, en el año 2007, en gran parte causado por el retraso en la construcción de la central hidroeléctrica de Garabito. Y a pesar de todas las limitaciones políticas recientes, el instituto ha logrado reducir la duración media de las (muy poco frecuentes) interrupciones en el suministro de servicios: de 21,1 horas en el año 2000 a 14,8 horas en el año 2009 (SIICE 2011).

Desde 1963, el instituto también se ha responsabilizado de la prestación de servicios de telecomunicaciones, los que hasta entonces habían estado en su totalidad bajo el control de corporaciones privadas extranjeras. Y "a pesar de que durante mucho tiempo las telecomunicaciones fueron percibidas como la hermana menor de la electricidad, también aquí la empresa ha logrado grandes avances en la extensión de la red a nivel nacional, aplicando el mismo patrón de inclusión geográfica y social que caracteriza a la red eléctrica" (Hoffmann 2007: 11). El instituto ha desarrollado una red de telefonía que cubre todo el país, la que también ha contribuido a la expansión de los servicios eléctricos. El ICE modernizó el sistema de telecomunicaciones hasta instalar una red telefónica actualizada en términos tecnológicos, integral y asequible. A pesar de que los dos sectores -telecomunicaciones y electricidad-son muy diferentes desde un punto de vista técnico, la planificación estratégica y la gestión de ambos segmentos se complementaban entre sí desde el punto de vista financiero. Dado que "el sector telefónico era más rentable, requería inversiones de menor cuantía y tenía una recuperación a más corto plazo que el sector eléctrico", fue posible que durante muchos años "el sector telefónico internacional financiara parte de la expansión del sector eléctrico nacional y los programas de telefonía rural” (Jiménez Gómez 2009: 189).

En el sector de las telecomunicaciones, la empresa estatal subsidiaba las tarifas para acceder al servicio telefónico y realizar llamadas locales, al tiempo que promovía programas de extensión en las zonas rurales, incluyendo la instalación de centros de telefonía pública en régimen de concesión en pueblos y pequeñas ciudades. Asimismo, en contraste con el enfoque prevalente durante décadas en la mayoría de los países del Sur, en Costa Rica no se concebía a las telecomunicaciones como un artículo de lujo destinado a las élites urbanas, sino como un componente esencial de la integración y el desarrollo nacional, posibilitando así la extensión de una de las redes de telefonía más densas y socialmente más equilibradas a nivel mundial (ITU 2006). En consonancia con otras particularidades de su 
modelo de desarrollo, en un sentido más general, "la modalidad de acceso a las telecomunicaciones de Costa Rica era similar al sistema inclusivo e integral típico de los países ricos, a pesar de haber sido desarrollada en las condiciones propias de un país pobre" (Hoffmann 2007: 12) ${ }^{3}$.

\section{SOSTENIBILIDAD AMBIENTAL}

El ICE ha contribuido enormemente a consolidar la posición actual de Costa Rica como uno de los países líderes en la producción de energía limpia. La electricidad producida a partir de fuentes renovables ha sido durante mucho tiempo un componente esencial de la política energética. El desarrollo del país en esta materia no se puede explicar sólo en función de la carencia de hidrocarburos o la amplia disponibilidad de recursos hídricos; de hecho, el potencial hidroeléctrico costarricense es mucho menor que el de varios otros países de América Latina. Asimismo, a diferencia de otros pequeños países del Sur que dependen casi por completo de la energía hidroeléctrica, Costa Rica ha desarrollado múltiples opciones en base a diversas fuentes renovables (SIICE 2011). Costa Rica también exhibe una intensidad de energía eléctrica relativamente baja en comparación con otros países (Ziesing 2012).

El compromiso con la utilización de fuentes renovables fue instituido en el propio decreto fundacional del ICE del año 1949. La legislación posterior confirmó y profundizó la vocación ambientalista del instituto (Fernández Robles 1985). En 1953, la Ley 1657 estableció una reserva de energía hidráulica que garantizaba la protección de varias fuentes de agua utilizables para la generación de electricidad. En 1976, la Ley 5961 responsabilizó al ICE de la investigación, exploración y explotación de los recursos geotérmicos del país. En 1980, la Ley 6.449 declaró el interés del país en la promoción de la energía eólica, en particular en comunidades rurales aisladas de la red eléctrica nacional.

Como muestra el Cuadro 2, la capacidad de generación instalada sigue dependiendo en gran medida de fuentes renovables: la energía de origen hidroeléctrico, geotérmico, eólico o biomasa representa más del $80 \%$ de la matriz eléctrica nacional. En términos de consumo, un impresionante 93\% de la energía consumida en el año 2010 derivó de fuentes renovables.

3 Nuestro análisis está centrado en el sector eléctrico. Para un estudio más detallado de las características y desafíos del sistema de telecomunicaciones de Costa Rica, incluyendo una defensa muy personal y apasionada del papel del ICE y de sus contribuciones históricas al desarrollo nacional frente a las reformas de mercado, véase Fumero Paniagua (2006). El sector de las telecomunicaciones ha sido completamente liberalizado en Costa Rica: desde el año 20 i el ICE debe competir con las empresas transnacionales más poderosas de la región. 


\section{Cuadro 2: Capacidad de generación instalada en Costa Rica y porcentajes de generación por fuente (ańo 2010)}

\begin{tabular}{ccc} 
Fuente & $\begin{array}{c}\text { Capacidad de generación } \\
\text { instalada }\end{array}$ & Energía generada \\
\hline Hidroeléctrica & $67 \%$ & $76 \%$ \\
Geotermal & $7 \%$ & $12 \%$ \\
Eólica & $5 \%$ & $4 \%$ \\
Biomasa & $2 \%$ & $1 \%$ \\
Termal & $19 \%$ & $7 \%$
\end{tabular}

Fuente: Adaptado de Jiménez Gómez (2011).

La capacidad instalada, sin embargo, no sería suficiente frente a la tasa actual de crecimiento de la economía y su alta dependencia del petróleo importado (De la Torre 2010). Los críticos neoliberales han utilizado perversamente este argumento para reforzar su demanda de mayor liberalización. Sin embargo, los datos objetivos demuestran que la alegación de que no se han explotado adecuadamente las fuentes renovables es absolutamente errónea. De hecho, el verdadero problema del país reside en la demanda de hidrocarburos del sector del transporte, que consume aproximadamente el $80 \%$ de todos los productos derivados del petróleo que ingresan a Costa Rica. La electricidad sólo representa el 20\% de la energía consumida en el país, de la cual sólo el 5\% se produce con derivados petrolíferos (SIICE 2011).

A largo plazo, sin embargo, los impactos del cambio climático en el suministro eléctrico en América Central -una de las regiones del mundo que previsiblemente serán más afectadas- son preocupantes (Ventura et al. 2011). La modificación del régimen de lluvias en el istmo es evidente desde hace ya varios años. En 2011, Costa Rica experimentó un ligero descenso en la producción de energía, a pesar de que la planta hidroeléctrica Pirrís fue inaugurada en septiembre de ese mismo año ańadiendo $134 \mathrm{MW}$ a la red; en consecuencia se tuvo que recurrir a más electricidad producida a partir de la quema de combustibles fósiles (La Nación 2012).

Ante la creciente demanda energética, la discusión acerca del aprovechamiento del potencial geotérmico del país ha cobrado impulso. El problema es que a pesar de que varios estudios han demostrado que el perfil geológico de Costa Rica ofrece posibilidades auspiciosas, la mayoría de los lugares óptimos para la generación geotérmica se encuentran alrededor de volcanes en parques nacionales (Arias Molina y Chaves Mora 2012), dando lugar a un difícil dilema en el diseño de políticas públicas. 


\section{EL ICE y SUS TRABAJADORES}

A lo largo de su historia, las juntas directivas del instituto han mantenido relaciones directas y abiertas con los funcionarios, representados por el Frente Interno de Trabajadores (FIT-ICE), una organización que amalgama a los diversos sindicatos de la empresa.

Varios presidentes y ministros de Costa Rica han negociado en persona con los sindicatos del instituto y, cuando la integridad institucional del ICE fue amenazada en el pasado reciente, otros sindicatos se han unido en apoyo de la empresa y de sus trabajadores. En mayo de 2003, por ejemplo, la Asociación Nacional de Empleados Públicos (ANEP), una de las entidades gremiales más grandes del país, organizó una huelga nacional en rechazo a la negativa de gobierno a liberar los fondos necesarios para desarrollar nuevos proyectos del ICE (La Nación 2003), demostrando el fuerte arraigo social del instituto.

Durante las últimas décadas el ICE invirtió cuantiosos recursos en la expansión de la capacidad técnica de sus trabajadores, ofreciendo programas de capacitación para ingenieros, cuadros gerenciales y empleados técnicos y administrativos. El instituto también ha proporcionado becas para cursar estudios superiores y ha organizado visitas de estudio a otras empresas en el extranjero. Desde su creación, el instituto ha sido reconocido por la alta calidad de sus trabajadores, en base a una estricta selección de personal y a una decisión estratégica de promover el desarrollo de la capacidad endógena. El ICE ha puesto en marcha varios programas de formación e investigación en colaboración con la Universidad de Costa Rica. Asimismo, ha incentivado la permanencia de los trabajadores, a través de sistemas de ahorro mutuo y fondos de garantías (Fernández Robles 1985, WildeRamsing y Potter 2006).

El desarrollo de la capacidad técnica interna también ha contribuido al liderazgo del ICE en el campo de la energía renovable. El instituto ha desarrollado habilidades técnica atípicas en la mayoría de los países del Sur, generando ventajas competitivas en un contexto internacional en el que el acceso relativamente simple y barato a la tecnología necesaria para operar plantas de generación térmica ha determinado que otros países no se arriesguen a impulsar proyectos de energía renovable, técnicamente más complejos. Por otra parte, sus capacidades técnicas también le han otorgado un mayor grado de autonomía frente a intereses cortoplacistas, ya que le permite al ICE el diseño de una estrategia energética nacional en lugar de tener que depender de empresas extranjeras para la realización de estudios prospectivos (Wilde-Ramsing y Potter 2006). 
Durante la década pasada, los trabajadores del ICE han organizado varias acciones sindicales en defensa del carácter público del instituto. En setiembre de 2011, los trabajadores emitieron una declaración pública en la que resumían la perspectiva sindical sobre las reformas de mercado (FITICE 2011: 1):

Quienes impulsan la privatización del sector eléctrico, no se detienen ante nada, mienten y amedrentan para lograr sus fines. Mentiras como que el ICE no tiene la capacidad técnica, ni económica para desarrollar nuevos proyectos y que como consecuencia, en el corto plazo, el país va a sufrir desabastecimiento y graves apagones, son algunos de los argumentos con que han querido manipular y asustar a la opinión pública.

Por el contrario, las organizaciones del ICE hemos demostrado técnica, profesional y políticamente, que todo lo dicho es mentira y que si al ICE se le permite cumplir con el desarrollo eléctrico nacional, conforme con su planificación, si se le permite acceder a recursos financieros sanos y si se le permiten tarifas eléctricas para cubrir los costos, el país tendría asegurada la atención de la demanda futura.

Investigaciones previas han puesto de relieve que la capacidad del ICE para planificar a largo plazo y utilizar fuentes de energía renovables están asociadas a la particular relación que el instituto ha establecido con la sociedad costarricense, visible en el arraigo de la empresa entre organizaciones de la sociedad civil, sindicatos, intelectuales y la población en su conjunto (Wilde-Ramsing y Potter 2006).

Después de más de seis décadas, el apoyo público a la propiedad estatal y la gestión de los servicios de electricidad (y de telecomunicaciones) sigue siendo fuerte en el país, como una encuesta anual de opinión pública realizada por la Universidad de Costa Rica lo revela. En el año 2000, en el apogeo de las movilizaciones sociales en defensa del instituto, el $72 \%$ de la población estaba en contra de la privatización del ICE; en el año 2011, después de muchos años de campañas mediáticas contra las entidades públicas financiadas por las cámaras empresariales, el $64 \%$ de la los encuestados todavía expresaba la misma opinión (Poltronieri 2011).

Gran parte de la imagen positiva del instituto es el producto de la existencia de una tecnocracia interna robusta, comprometida con la misión institucional y muy activa en la defensa y difusión de los logros de la empresa. Este grupo está integrado por personal profesional que opera con relativa autonomía técnica y de gestión. De acuerdo con la descripción 
proporcionada por un investigador local (Jiménez Gómez 2009: 327), él mismo miembro de este grupo:

Son funcionarios del ICE con diferentes niveles jerárquicos que forman parte del sector eléctrico, con conocimiento sobre el funcionamiento de éste. Circunscritos por lo general a la labor del ICE, que defienden la forma cómo el ICE ha llevado a cabo sus acciones, buscando mantener o mejorar la situación existente.

En general tienen como objetivo mantener el papel del ICE como actor relevante en el sector, como forma para asegurar la prestación de los servicios eléctricos con fuentes renovables bajo adecuados estándares de calidad y con solidaridad social. Además de defender sus beneficios como empleados [...].

Las preferencias han estado asociadas hacia la participación pública preponderante en todas las cadenas de valor, fortalecer al ICE y dejarlo que pueda llevar a cabo las inversiones necesarias para abastecer la demanda, por medio de un modelo solidario en donde la electricidad se vea como un servicio público y no como una mercancía [el énfasis es nuestro].

\section{LA LIBERACIÓN DEL MERCADO ELÉCTRICO Y LA CORPORATIZACIÓN DEL ICE}

El modelo costarricense de desarrollo ha estado sufriendo una crisis paulatina durante los últimos treinta ańos. Ya en la década de 1970, la economía nacional sufrió las consecuencias del creciente costo del petróleo y el deterioro de los precios del café y otros productos agrícolas. El acuerdo firmado con el Fondo Monetario Internacional (FMI) en el año 1982 dio inició a una fase prolongada de ajuste estructural. En las décadas de 1980 y 1990 el país se vio afectado por el aumento de la violencia política en los países vecinos, así como por la explosión de la crisis de la deuda latinoamericana. En tal contexto, los políticos conservadores y representantes de la élite económica comenzaron a presionar por un cambio orientado a la reducción del déficit fiscal, la desregulación, la privatización y la adopción de una estrategia de crecimiento basada en las exportaciones (Rovira Mas 1989).

Desde mediados de 1980, una serie de gobiernos neoliberales ha promovido reformas radicales en el modelo de solidaridad que había hecho posible la singular evolución de los servicios públicos en Costa Rica. El primer gobierno de Oscar Arias (1986-1990) privatizó empresas públicas del grupo CODESA y habilitó la liberalización del sector financiero. Costa Rica experimentó una reforma del Estado más gradual (en comparación con la mayoría de los otros países latinoamericanos), pero que permitió 
acabar con los monopolios estatales en diversas áreas de la economía y aprobar nueva legislación dirigida a reducir los beneficios sociales que habían caracterizado durante mucho tiempo al llamado Estado Social de Derecho (Cortés Ramos 2009).

A pesar de la fuerte oposición social a las políticas de mercado, las reformas neoliberales ya han debilitado las raíces del sistema eléctrico y cuestionado las competencias y las capacidades del ICE en particular. Los mecanismos más visibles utilizados para reformar el sector eléctrico han sido los siguientes (véase SIICE 2011):

1. El acatamiento de los postulados básicos del Consenso de Washington, que asume la austeridad presupuestaria como principio rector $\mathrm{y}$ concibe a las inversiones públicas como meros gastos que deben ser reducidos o reorientados a otros fines.

2. Las presiones gubernamentales persistentes en la gestión del ICE, demandando un excedente financiero para reducir el déficit fiscal y reduciendo la capacidad del instituto para invertir de forma autónoma en el desarrollo del sector eléctrico.

3. El mayor control político en la planificación del sector eléctrico, dificultando la ejecución de nuevos proyectos de infraestructura del ICE y reduciendo la autoridad del instituto para establecer tarifas apropiadas para el sector.

4. Propuestas legislativas radicales, como el combo eléctrico (que será explicado con más detalle más adelante) dirigidas a privatizar la producción de energía.

5. Campañas mediáticas agresivas y sistemáticas, financiadas por las cámaras empresariales con el propósito de contrarrestar la imagen positiva del ICE en la opinión pública costarricense.

\section{El CONSENSO NEOLIBERAL CONTRA EL ICE}

Las primeras reformas de mercado en el sector eléctrico se implantaron en la década de 1990, a partir de la aprobación de la Ley N. ${ }^{\circ} 7.200 / 1990$ y la Ley N. ${ }^{\circ} 7.508 / 1994$, que ampliaron la participación del sector privado en la generación de energía. Hasta entonces, el sistema eléctrico se había desarrollado como un cuasi-monopolio público, ya que el ICE producía el 90\% de la energía consumida en el país.

En el transcurso de las décadas 1980 y 1990, las tensiones sociales y políticas se agudizaron en todo el país (Rovira Mas 2001). Hasta 
entonces, la movilización social había impedido la aplicación de los planes neoliberales más ambiciosos, tales como la desregulación del sector de telecomunicaciones a través de la concesión de servicios de telefonía móvil a la transnacional de matriz luxemburguesa Millicom en el año 1987.

La ofensiva neoliberal en los dos sectores cubiertos por el ICE, electricidad y telecomunicaciones, cobró impulso bajo otro gobierno del Partido de Liberación Nacional (PLN, el mismo grupo político que había sido fundado en 1951 como la continuación del Partido Social Demócrata), encabezado por José María Figueres Olson -hijo del padre fundador de la socialdemocracia costarricense, José Pepe Figueres-, quien propuso desde su presidencia la privatización de una amplia gama de empresas públicas (Haglund 2006, 2011). Ante una gran oposición política y social, Figueres optó por buscar un acuerdo bipartidista con el Partido de Unidad Social Cristiana (PUSC), dirigido por Rafael Calderón Fournier -hijo de Rafael Calderón Guardia-. El resultado fue el pacto Figueres-Calderón de 1995, firmado por el Presidente y su predecesor inmediato. El acuerdo simbolizó el fin de toda una era, ya que sus signatarios eran los vástagos de los principales dirigentes de las dos partes enfrentadas en la guerra civil de 1948.

Los dos partidos tradicionales acordaron impulsar la privatización de ICE, pero de forma encubierta. La opción elegida fue modificar su estructura interna y romper el monopolio del instituto en el sector de las telecomunicaciones habilitando la competencia privada. El proyecto inicial, enviado a la Asamblea Nacional en setiembre de 1996, constaba de tres componentes: 1) una nueva ley orgánica para el ICE que separaba los sectores de telecomunicaciones y electricidad, los cuales pasaban a ser gestionados por dos entidades independientes; 2) una nueva ley para regular el sector eléctrico; y 3) una nueva ley para regular el sector de las telecomunicaciones (Monge 2000).

El gobierno también creó un comité de expertos para el análisis de posibles soluciones a la deuda interna del país, que derivó en la publicación de un informe con el apocalíptico título de Mañana Será Tarde, en el que se recomendaba la privatización de las centrales eléctricas (Comisión para el Análisis de la Deuda Interna 1996). A pesar de que el comité había sido supuestamente creado para buscar soluciones al creciente déficit fiscal, "hubo un alto grado de sospecha en torno a las actividades de este grupo, ya que sus miembros podrían exagerar la gravedad de la crisis ante la posibilidad de obtener beneficios personales con la privatización del ICE” (Haglund 2006: 13). 
El vencedor de las elecciones de 1998 fue el PUSC, liderado por Calderón. El gobierno entrante decidió seguir adelante con el paquete de reformas pendientes y envió la ley de electricidad al parlamento para su aprobación legislativa. Sin embargo, antes de enviar los otros dos proyectos de ley, el Presidente convocó al Foro de Concertación Nacional procurando un mayor apoyo de las asociaciones empresariales y los sindicatos. Contando con el sustento ferviente otorgado por el sector privado y el apoyo un tanto menos entusiasta del sindicalismo, el gobierno decidió solicitar la aprobación legislativa del paquete completo.

\section{LA MOVILIZACIÓN CONTRA EL COMBO ELÉCTRICO DEL AÑO 2000}

El 20 de marzo del año 2000, la Asamblea Legislativa aprobó el proyecto popularmente conocido como el combo eléctrico. La propuesta, supuestamente orientada a la modernización del ICE, proponía la liberalización de las telecomunicaciones y la generación de electricidad, así como una profunda reestructuración de ambos sectores.

Los dos principales partidos confiaban que la fusión de los tres proyectos en un solo paquete aceleraría el proceso legislativo. En realidad, terminó siendo la estrategia política equivocada, ya que facilitó la convergencia de actores sociales muy diversos en una heterogénea coalición de resistencia al combo. Los sindicatos del ICE se retractaron de su tímido apoyo inicial y poco después otros gremios también expresaron su oposición, temerosos de que iniciativas legislativas similares podrían afectar la seguridad del empleo y la cuantía de los beneficios sociales en sus propias áreas de trabajo. El movimiento estudiantil también manifestó su oposición a lo que ellos percibían como un componente de un programa mucho más amplio de reformas neoliberales. Los ambientalistas también se unieron al bloque opositor, preocupados por los posibles efectos del artículo 119, que autorizaba la construcción privada de nuevos proyectos hidroeléctricos en reservas naturales. En resumen, las movilizaciones emergentes en torno al combo fueron organizadas por un movimiento social plural, multisectorial e intergeneracional, que fue apoyado activamente en diferentes regiones de todo el país, constituyendo la lucha social más importante en la historia de Costa Rica en varias décadas (Cortés Ramos 2009).

Un sector social relevante en la movilización contra el combo fue el movimiento campesino. Preocupados por la caída de los precios internacionales, los productores rurales habían organizado protestas en demanda de un mayor apoyo gubernamental, que luego se fusionaron con las manifestaciones callejeras en torno al combo. 
En el campo, en particular, la apreciación del papel del ICE como una muy estimada entidad promotora del desarrollo y la integración social fue determinante; y fue en las áreas rurales donde la eventual privatización generó los mayores temores, ante la posible pérdida de los aportes del ICE al desarrollo (Hoffmann 2007: 17).

El combo dejó en evidencia los vínculos e intereses comunes que ensamblan a las diferentes fracciones de la clase dominante costarricense. El proyecto contó con el apoyo entusiasta de las asociaciones empresariales y de una amplia coalición de políticos neoliberales, incluidos los líderes de los dos partidos tradicionales -quienes tenían intereses creados en las empresas que operaban en los sectores de la electricidad y de las telecomunicaciones-. Por otra parte, las movilizaciones confirmaron la percepción positiva de las empresas estatales, y del ICE en particular, en la sociedad costarricense. A pesar de costosos anuncios contratados en la televisión y en la prensa, la ciudadanía seguía percibiendo a términos tales como modernización y liberalización como meros eufemismos que trataban de ocultar el objetivo real de la privatización (Cortés Ramos 2009).

Además del resultado inmediato de las movilizaciones -la suspensión de la propuesta de reestructuración de la energía y las telecomunicacionesmuchos de los entrevistados para esta investigación destacaron el hecho de que las movilizaciones contra el combo tuvieron un impacto a más largo plazo: lo modificación y la postergación de la agenda neoliberal de privatización no sólo de ICE , sino también de muchas otras empresas estatales.

Al cabo de dos semanas, cuando las movilizaciones no mostraban signos de abatimiento, el gobierno decidió, en abril de 2000, retirar el proyecto. El debate político sobre el papel del ICE y del sector privado en las dos áreas cubiertas por el instituto, sin embargo, continúa hasta la fecha.

\section{LA CORPORATIZACIÓN DEL ICE}

Desde mediados de la década de 1990, el ICE ha sufrido un proceso interno de mercantilización. Entre 1994 y 1998, el Gobierno decidió seguir la tendencia mundial hacia la liberalización de servicios públicos. La decisión implicaba también cambiar la estructura institucional y los marcos de gestión de ICE, sin desmantelarlo por completo y preparando las condiciones para la futura competencia con operadores privados en un mercado liberalizado. Con ese objetivo en mente, a partir de 1996 el ICE comenzó a aplicar reformas internas que incluyeron "la definición de un plan estratégico, la implementación de una nueva estructura administrativa, la creación de perfiles de puestos y el levantamiento de competencias para 
la calificación del personal y selección de los niveles de jefatura" (Fumero Paniagua 2006a: 82).

Uno de las primeras y más cruciales reformas internas fue la separación administrativa y financiera de los sectores energía y telecomunicaciones. Esa decisión, que fue presentada como un medio para maximizar el potencial de desarrollo de cada sector y aumentar la eficiencia general de la empresa, en la práctica derivó en mayores costos y la pérdida de sinergias internas. La separación quedó incompleta en 1998, debido al cambio de gobierno, pero "el híbrido resultante hace más difícil la coordinación interna y, lejos de fortalecer al instituto, facilitó su desintegración" (Fumero Paniagua 2006a: 85).

En base a entrevistas con miembros de tres entidades gremiales -la Asociación Sindical de Empleados Industriales de las Comunicaciones y la Energía (ASDEICE), la Asociación Nacional de Trabajadores y Técnicos en Energía y Comunicaciones (ANTTEC) y el Sindicato de Ingenieros y Profesionales del ICE, RACSA y CNFL (SIICE)- hemos reconstruido analíticamente el proceso iniciado hace dos décadas y que continúa hasta el presente. De acuerdo con los entrevistados, las previamente existentes cinco subgerencias se fusionaron en sólo dos (energía y telecomunicaciones) $\mathrm{y}$ todos los procedimientos internos tuvieron que emigrar a una nueva estructura administrativa con nuevos objetivos. Con el paso del tiempo, se creó una tercera unidad centrada en la prestación de apoyo gerencial y administrativo a los dos sectores, restableciendo en cierto grado la estructura anterior, pero muchos de los vínculos internos para entonces ya habían sido cortados.

En una entrevista realizada a Fabio Chávez (presidente de ASDEICE) en mayo de 2001, el líder sindical afirmaba que:

La reestructuración interna supuestamente permitiría desarrollar una nueva visión estratégica basada en los principios del mercado, pero durante algunos meses o años no hubo claridad ni sobre los roles ni sobre las responsabilidades de cada unidad. Muchos servicios y funciones internas se fragmentaron, lo cual llevó en ocasiones a situaciones de competencia en lugar de la cooperación al interior del Instituto. El ICE también tuvo que hacer frente a la duplicidad de recursos y la falta de coordinación entre el sector energía y el sector telecomunicaciones, lo cual cuestionaba todo el sentido de la reforma, la que se suponía iba a dar lugar a mejoras de eficiencia y eficacia que no se concretaron. 
Otra cuestión muy criticada por los sindicatos y los investigadores locales ha sido el énfasis puesto por los reformistas en la externalización o tercerización de servicios. En lugar de depender de sus propios trabajadores y de los recursos internos, el instituto comenzó a subcontratar tareas de apoyo en las áreas de limpieza, alquiler de oficinas, centros de llamadas, seguridad, reparación y mantenimiento de equipos y capacitación del personal, entre otras. Incluso servicios estratégicos como la instalación y reparación de líneas de energía y de telecomunicaciones fueron subcontratados a empresas privadas. En gran medida, la dependencia de contratos externos fue percibida por los nuevos administradores como una forma de cumplir con la demanda de excedentes presupuestarios y de reducción de costes internos que llegaba constantemente desde el Ministerio de Hacienda. La tercerización, sin embargo, en muchos casos condujo a mayores costos en lugar del ahorro.

La corporatización también incluyó una convocatoria a los trabajadores del ICE para beneficiarse de la jubilación anticipada, mientras que otros fueron invitados a abandonar el instituto para crear nuevas empresas privadas y vender sus servicios al ICE para hacer el mismo trabajo que realizaban hasta entonces como funcionarios. Quienes se acogieron al esquema de movilidad laboral fueron precisamente aquellos funcionarios que por sus competencias técnicas contaban con mejores posibilidades de inserción en el mercado laboral privado nacional o extranjero. De esta forma, "el ICE pagó millonarios estímulos para deshacerse de sus mejores y más experimentados técnicos y profesionales" (Fumero Paniagua 2006a: 88). Por otra parte, la contratación indirecta de personal a través de tercerizaciones derivó en otros problemas, en particular,

la pérdida paulatina de la identificación con la Institución, la mística que llevó al ICE a convertirse en la más grande empresa de Centro América y el incremento en las acciones de fraude interno, al no existir una relación directa y por lo tanto de mayor compromiso con la Institución (Fumero Paniagua 2006a: 88).

También se creaba una dependencia de las empresas contratadas, que no le permitiría al ICE reaccionar en caso de contingencias, al menos con la misma agilidad que le proporcionaría el disponer de recursos técnicos propios.

\section{EL DEBATE ACTUAL EN TORNO A LA LIBERALIZACIÓN DEL SECTOR ELÉCTRICO}

En los años posteriores a la movilización social contra el combo eléctrico, los reformistas neoliberales han seguido reclamando la liberalización, la desregulación y la eventual privatización del sector eléctrico. En junio de 
1996, el titular del Ministerio de Hacienda declaró que la población debía entender que el Estado no podía seguir invirtiendo como en ańos anteriores, y que los nuevos proyectos debían desarrollarse a través de concesiones a operadores privados o que se debía avanzar hacia la plena privatización (Noguera 1996). La opción propuesta entonces consistía en vender las plantas hidroeléctricas en manos del ICE y utilizar el dinero entrante para financiar la construir de nuevos proyectos con gestión privada.

En los últimos años, quienes abogan por reformas neoliberales han desarrollado una argumentación más sofisticada en demanda de reformas estructurales, aludiendo a una serie de problemas supuestamente evidentes en el sector eléctrico. Tales argumentos fueron resumidos en la exposición de motivos de la Propuesta 17.812, enviada al Parlamento en agosto de 2010, donde se destaca: 1) la presunta vulnerabilidad externa del país a cambios en el mercado mundial de la energía, debido a la dependencia creciente de combustibles fósiles importados; 2 ) inversiones supuestamente insuficientes, con riesgos evidentes de apagones y de deterioro de la calidad de los servicios; 3) supuestas barreras legales que impedirían nuevas inversiones; 4) la composición teóricamente no competitiva del sistema eléctrico costarricense, que dificultaría la inversión y empeoraría la calidad del suministro; y 5) una correlación aparentemente inapropiada entre la demanda y la oferta, que impediría a los grandes consumidores dedicarse a la autogeneración de energía.

El proceso de liberalización del sector eléctrico cobró impulso en 2007, en el contexto de una aguda crisis energética que provocó apagones repetidos, principalmente causados por una grave sequía que afectó a América Central ese año. El entonces Presidente, Óscar Arias, declaró que la crisis había sido producida por varios factores, incluida la negligencia de gobiernos anteriores al limitar la capacidad del ICE para realizar las inversiones necesarias en la generación de energía, políticas equivocadas sin una planificación adecuada, y "prejuicios ideológicos" evidentes en la "demonización" de la participación del sector privado en el sector eléctrico (Mayorga 2007).

Argumentos similares ya habían sido expuestos en las páginas de opinión de los diarios principales. La página editorial de La Nación retrataba al ICE como una empresa cada vez más dependiente de las plantas térmicas, como consecuencia de "la burocracia técnica y administrativa con costos innecesarios para el usuario". Los principales culpables, desde la perspectiva del periódico conservador, eran los sindicatos del ICE. La solución propuesta era aprobar lo antes posible la ley de modernización del ICE y normas conexas, "con el objetivo de permitir que el sector privado coadyuve con el esfuerzo nacional de suministrar energía abundante, a 
mejores precios y razonablemente limpia” (La Nación 2007).

Tanto el diagnóstico del problema como las soluciones propuestas por los defensores del mercado ignoran una obvia paradoja. La crisis energética ha sido catalizada por el proceso previo de liberalización, en el contexto de las reformas legales (leyes N. ${ }^{\circ} 7.200$ y N. ${ }^{\circ} 7.508$ ) aprobadas en la década anterior. La legislación precedente ya había concedido el acceso de los operadores privados a un importante recurso natural, agua para la generación de energía, con la condición de que el ICE se vería obligado a comprar la energía generada por el sector privado a tres veces su costo de producción.

Durante el año 2009, dos proyectos concretos de liberalización se presentaron a la Asamblea Legislativa, para luego ser unificados en un proyecto único: el Expediente N. ${ }^{\circ}$ 17.666. El objetivo principal de esta iniciativa es la liberalización total del sector eléctrico, aplicando una estrategia similar a la que fuera utilizada en el sector de las telecomunicaciones. La justificación destaca la necesidad de asegurar un suministro confiable de energía, basado en la eficiencia y la competencia que se lograrían con la entrada de proveedores privados de energía en el mercado nacional. El texto del proyecto no presta atención al hecho de que el modelo de Costa Rica ya ha sido elogiado internacionalmente por ser desde hace ya tiempo el más eficiente, eficaz, socialmente igualitario y ambientalmente sostenible de la región (CEPAL 2010).

Al momento de redacción de este texto, la reforma del sistema eléctrico sigue estando en el centro de acalorados debates en los medios de comunicación y en el parlamento. Varias propuestas están actualmente bajo consideración de la Asamblea Legislativa y no hay ninguna certeza sobre el cronograma o el contenido exacto de la reforma a ser aprobada. En el centro de la controversia se ubica el grado de participación permitido al sector privado. Las opciones propuestas por las diversas bancadas van desde la plena liberalización y recortes radicales en las responsabilidades y los objetivos del ICE hasta el reforzamiento del modelo sin cambios sustanciales en la estructura institucional actual.

La primera iniciativa tiene sus raíces en la legislación heredada de la administración Arias. Promueve la liberalización más completa del sector eléctrico. La fracción neoliberal más radical, el Movimiento Libertario (ML) aboga por esta propuesta. Entre otros puntos, se propone la creación de un mercado mayorista que permita transacciones libres entre generadores, distribuidores y otros agentes activos en el sector eléctrico. De acuerdo a esta propuesta, el ICE pasaría a competir con cualquier otra empresa, nacional o extranjera, sin que hubiera ninguna restricción a la cantidad de 
energía a ser producida por la generación privada.

El segundo proyecto es la Ley General de Electricidad (Expediente N. ${ }^{\circ}$ 17.812), iniciado por el actual gobierno de Laura Chinchilla (2010-2014) y apoyado en el Parlamento por el PLN. Este proyecto también busca la liberalización del sector, pero con cierta moderación. Bajo el nuevo marco institucional propuesto, el ICE se mantendría como el mayor operador, pero facilita la mayor participación de los proveedores privados de energía.

También hay un proyecto presentado por el consorcio formado por las cooperativas, Coneléctricas, cuyo objetivo es reforzar el modelo actual, al tiempo que promueve el papel de las cooperativas en la prestación de servicios de electricidad, tanto a nivel de la distribución como de la generación. Esta propuesta se centra en la mejora de la regulación, manteniendo el control y la planificación de la distribución en manos del ICE (Coopeléctricas et al. 2010).

Por último, también existe un proyecto menos ambicioso, la Ley de Contingencia Eléctrica (Expediente N. ${ }^{\circ} 18.093$ ), también enviado por la administración Chinchilla, centrado en la ampliación de la cuota de generación privada. Esta propuesta ha sido concebida como una medida transitoria. Fue remitida al parlamento solicitando su urgente aprobación, y es de hecho una versión abreviada de la Ley General de Electricidad. A pesar de la retórica utilizada en su preámbulo, que alude al "fortalecimiento" del ICE, el proyecto tiende a reducir su autonomía, en contradicción con las competencias en materia de planificación que la constitución nacional otorga al instituto. El proyecto de ley autoriza a proveedores privados a vender electricidad directamente a grandes consumidores, entendidos como aquellos con necesidades de energía iguales o superiores a un megavatio, y les permite exportar sus excedentes al mercado regional centroamericano. El proyecto también aumenta el límite para la generación privada, de 20 a 30 MW y expande la cuota para la generación paralela del $15 \%$ a $25 \%$

\section{LOS DESAFÍOS ACTUALES}

\section{EL RIESGO DEL RETROCESO}

Un detallado análisis comparativo del sector eléctrico en la región centroamericana publicado hace una década presentaba un panorama muy sombrío, en el que Costa Rica era la única y brillante excepción:

Dentro de los aspectos negativos podrían enumerarse las menores inversiones privadas efectuadas bajo condiciones de mercado y sin la protección del Estado o de contratos específicos; el aumento de las 
pérdidas técnicas y no técnicas en la mayoría de los países; la débil expansión de la electrificación rural; el incremento notable de las emisiones contaminantes por un parque de generación con mayor participación de centrales termoeléctricas; la drástica reducción de la participación de fuentes nuevas y renovables (con excepción de Costa Rica); la alta concentración en la estructura del segmento de la distribución y la incipiente competencia en los mercados mayoristas (CEPAL 2003: 90).

Diez años después, las reformas de mercado actualmente en debate en la Asamblea Nacional, podrían significar que Costa Rica retroceda a la situación que caracteriza a los países vecinos. Los sectores neoliberales usan la sostenibilidad como argumento para justificar las reformas, pero sin reconocer una obvia contradicción. Por un lado, los proyectos neoliberales proclaman las virtudes de las fuentes renovables, pero sin tener en cuenta que la experiencia regional demuestra que la liberalización del sector eléctrico conduce a un nivel más alto de generación en base a centrales térmicas dependientes de combustibles fósiles, dado el mayor grado de volatilidad de los mercados liberalizados.

En resumen, el sistema de electricidad más exitoso de la región enfrenta hoy el grave riesgo de la regresión. Los principales desafíos que enfrenta el ICE se resumen en los siguientes pasajes de una entrevista que realizamos a Leonel Fonseca, ex Director General de la Autoridad Reguladora de los Servicios Públicos (ARESEP), en mayo de 2011:

Los planes que algunos grupos amigos del mercado presentan hoy como modelos para la reforma del sector eléctrico podrían destruir la esencia de un sistema que enorgullece a los costarricenses. Quienes acusan al ICE de ser ineficiente son los mismos grupos e individuos que han estado estrangulando su capacidad financiera durante los últimos seis gobiernos. La liberalización y la desregulación que exigen hoy en día va a destruir un modelo que es visto como ejemplar a nivel internacional.

Nuestros ciudadanos son muy conscientes de tres cosas. En primer lugar, que el ICE logró la electrificación de más del 99\% del país; en segundo lugar, que el ICE produce energía de primera clase, con fuentes renovables; y tercero, que la electricidad se suministra a precios asequibles y con criterios de solidaridad, ya que si usted vive en la ciudad y tiene un buen ingreso está subsidiando a los pobres que viven en zonas rurales.

No debemos olvidar que la ofensiva contra el ICE se intensificó en el año 2004, cuando el sector eléctrico pasó a estar controlado por 
asesores muy bien pagados de la UCCAEP [la Unión de Cámaras y Asociaciones de la Empresa Privada]. Para mí es muy obvio que quienes defienden estas propuestas están representando los intereses de las grandes empresas. Quieren redefinir la electricidad como un producto puramente comercial, no como un servicio público. La UCCAEP y sus aliados quieren un nuevo sistema en el que las empresas privadas pueden generar y vender electricidad, pero sin pensar en los factores sociales y económicos relacionados con el desarrollo del sistema eléctrico. Esto es lo que yo llamo la teoría del lomito. Quieren matar a la vaca sólo para obtener la carne de mejor calidad y luego dejar los huesos y las entrańas menos apetecibles para el ICE y para las cooperativas y sociedades municipales.

Lo que quieren es vender electricidad a los grandes consumidores, incluyendo grandes empresas como Intel, Holcim y Cemex. Y los grandes consumidores quieren tener la libertad de producir su propia energía o importarla de otros lugares, sin verse obligados a comprarle al Estado, e incluso exportar cualquier excedente. Eso crearía un gran desequilibrio en la generación de energía.

\section{¿QUIÉNES PROMUEVEN Y QUIÉNES SE OPONEN A LAS REFORMAS DE MERCADO?}

La modificación de la estructura económica del país en las últimas décadas ha dado lugar a una reconfiguración del sistema político nacional. El PLN, por ejemplo, ha pasado de ser el partido que había promovido el desarrollo de Costa Rica como un Estado de Bienestar a ser el principal defensor de los intereses del gran capital. La metamorfosis ha desconcertado a gran parte de su electorado tradicional. La reciente serie de gobiernos del PLN ha priorizado las demandas de los sectores económicos emergentes hacia una mayor liberalización y desregulación de la economía. Costa Rica está sufriendo un deterioro de su sistema político que demuestra la convergencia de intereses de las élites políticas y económicas de manera muy explícita:

Ha habido una superconcentración de los poderes en manos de lo que yo llamo una nueva oligarquía de carácter exportador, comercial y financiero voraz, que no responde a los intereses nacionales, sino que es una especie de intermediario entre las grandes transnacionales y los centros hegemónicos del poder capitalista [...]. Alrededor de la lucha contra el TLC se formó una coalición nunca antes vista, un alineamiento completo de los distintos sectores de esa neoligarquía alrededor del movimiento del 'Sí' al TLC (Vega Carballo 2008: 6)

$4 \quad \mathrm{El} 7$ de octubre de 2007 se realizó en Costa Rica un referéndum sobre el Tratado de Libre Comercio entre Estados Unidos, Centroamérica y República Dominicana 
La identidad y los intereses de los reformadores neoliberales se explicitaron en agosto de 2010, cuando se lanzó una costosa publicación de 92 páginas ominosamente titulada Costa Rica se Apaga. Coeditada por una revista de negocios (El Financiero) y la escuela de formación empresarial de mayor prestigio en la región (el INCAE, Instituto Centroamericano de Administración de Empresas), con fondos aportados por Tabacalera Costarricense (filial de Phillip Morris) y Gessa (una cadena de supermercados), la publicación presentó los argumentos a favor de reformas neoliberales radicales, prediciendo el inevitable colapso del sector eléctrico si no se instituyera la liberalización (El Financiero e INCAE 2010).

La entidad más activa en los recientes debates recientes en torno al ICE ha sido la Asociación Costarricense de Productores de Electricidad (ACOPE), afiliada a la UCCAEP, presionando a favor de la total liberalización del sector a nivel nacional y regional, exigiendo que se les permita vender energía a otros países centroamericanos.

Los argumentos teóricos que sustentan las propuestas neoliberales han sido suministrados por organizaciones como el INCAE y la Academia de Centroamérica, un centro de investigación privado que durante las últimas dos décadas ha aportado muchos de los funcionarios que ocupan puestos estratégicos en la administración pública y en el sector privado. La Academia ha tenido una influencia significativa en el diseño de políticas públicas, al ser "el grupo con pensamiento más homogéneo, objetivos más claros y con mayor capacidad de influir [...] en sectores relevantes de la sociedad, como los políticos y los empresarios" (Jiménez Gómez 2009: 325).

En la vereda de enfrente, los sectores sociales y políticos que estuvieron en la vanguardia de las manifestaciones del año 2000 contra el combo son en general los mismos que hoy expresan su oposición a las reformas de mercado. En una entrevista que tuvimos con Gerardo Fumero, ingeniero del ICE, se afirmaba en mayo de 2011:

Se nos ha acusado de intentar demonizar al sector privado, pero sólo estamos resistiendo la imposición de la agenda neoliberal. No estamos en contra del sector privado por sí mismo, pero en este país nadie puede negar que, con el fin de garantizar la prestación de servicios básicos a todos los ciudadanos independientemente de

(TLC o CAFTA-DR). El acuerdo había sido firmado en 2004 por los gobiernos de los cinco países miembros del Mercado Común Centroamericano (Costa Rica, El Salvador, Guatemala, Honduras y Nicaragua), la República Dominicana y Estados Unidos. El CAFTA-DR fue aprobado estrechamente con $52 \%$ de votos a favor. 
sus ingresos, la existencia de entes estatales autónomos como el ICE es esencial. Para preservar y expandir nuestro nivel de desarrollo necesitamos empresas públicas eficientes y bien gestionadas, con una visión clara y capaces de hacer planificación estratégica a largo plazo.

El pilar fundamental de la resistencia social a la privatización y la corporatización del sector eléctrico sigue estando constituido por los sindicatos del ICE. Las entidades gremiales han sido en gran medida la cara pública del instituto desde finales de la década de 1990. Los sindicatos del ICE han tenido que lidiar con fuertes campañas mediáticas lideradas por los principales diarios del país, que han exhibido a los trabajadores como el supuesto obstáculo a vencer en el camino a la modernización de la economía nacional en general y del sector eléctrico en particular.

La heterogénea coalición de movimientos sociales que surgió durante las manifestaciones del año 2000 se ha debilitado, pero la mayoría de los sectores que formaban parte de ella siguen opuestos a la liberalización. La izquierda costarricense (una mezcla heterogénea de grupos marxistas, nacionalistas y socialdemócratas) es anémica en términos de política institucional, pero es relativamente influyente entre los estudiantes y los profesores de las universidades públicas. Intelectuales progresistas han manifestado reiteradamente su oposición a las reformas mercantiles y su compromiso en defensa del Estado democrático social. Las organizaciones ambientalistas también forman parte de la coalición informal que apoya al ICE, en consideración de los efectos perjudiciales que la redefinición de la electricidad como un mero producto comercial podría tener en la mercantilización de la naturaleza, a pesar de mantener sus críticas al instituto ante el impacto real o esperado de los proyectos de generación eléctrica del ICE en comunidades indígenas y áreas protegidas.

Otros grupos de base comunitaria, incluyendo sectores vinculados a la Pastoral Social de la Iglesia Católica, también se oponen a la liberalización del sector eléctrico. Como ya ha sido mencionado, este tipo de entidades desempeñaron un papel significativo en el año 2000, cuando organizaciones locales en diferentes regiones del país emprendieron de forma espontánea el cierre de calles y otras manifestaciones en contra del combo.

Fueron precisamente muchas de estas comunidades las más afectadas por una serie de proyectos de generación hidroeléctrica, en su mayoría privados, en donde las afectaciones en sus entornos culturales productivos y sociales [...] buscaron minimizar los costos sin internalización de las externalidades negativas que estaban generando (Jiménez Gómez 2009: 323). 
En el Parlamento, la resistencia a la liberalización del sector eléctrico está representada por los legisladores de centro-izquierda del Partido Acción Ciudadana (PAC) y el más pequeño y más izquierdista Frente Amplio (FA). Las posiciones expresadas por los activistas políticos progresistas de alguna manera evocan las posiciones del PLN previas a la década de 1980. De hecho, varios dirigentes del PAC son cuadros socialdemócratas escindidos del partido liberacionista.

\section{CONCLUSIONES}

Retomando la idea del título: el ICE es una empresa pública excepcional en una atípica socialdemocracia en crisis. En consecuencia, tanto el significado concreto como el grado de mercantilización en el futuro están muy condicionados por factores nacionales difícilmente encontrados en otros países. A pesar de la persistente ola neoliberal, Costa Rica ingresó al siglo XXI preservando los rasgos primordiales de un tipo de Estado y una matriz de empresas públicas que siguen estando muy presentes en los debates actuales sobre el futuro del ICE y otras empresas públicas. Los valores predominantes se basan en una fuerte presencia del Estado como planificador, supervisor, regulador y proveedor directo de servicios públicos, en base a principios de equidad y de justicia social, principios muy arraigados en el funcionamiento de los organismos gubernamentales y en amplios sectores de la sociedad. Es en relación a esta particular configuración política y social que la discusión actual en torno al futuro del ICE debe ser entendida.

Durante las últimas seis décadas, la evolución de los servicios de electricidad ha sido en gran medida desarrollada en oposición a intereses comerciales privados, a diferencia de lo que se ha observado en la mayoría de los países del Sur. Nuestra investigación confirma los resultados de otros estudios que habían concluido que en contraste con la incrustación del ICE en la sociedad costarricense, sus lazos institucionales con las élites empresariales del país han sido históricamente débiles (Wilde-Ramsing y Potter 2006). Al respecto, será preciso realizar más investigación sobre la posible evolución de los lazos institucionales del ICE con las élites empresariales en los próximos años, considerando que el sector de las telecomunicaciones ya ha sido completamente liberalizado (desde el año 2011, lo que obliga hoy al instituto a competir con las dos corporaciones transnacionales que controlan el sector de las telecomunicaciones en América Latina (Telefónica y Grupo Carso) y que las propuestas de reforma que actualmente se debaten en el Parlamento conducen al sector eléctrico hacia un destino similar. 
Las investigaciones futuras sobre las empresas públicas de Costa Rica también deberán considerar el hecho de que el Estado en este país ha sido más benevolente que en otros lugares de América Latina, pese a la entusiasta adopción del paradigma neoliberal por los últimos gobiernos.

Los desafíos inmediatos del ICE -y de otras empresas estatales costarricenses- presuponen mantener la calidad de la gestión para el cumplimiento de su función social como empresa pública y la reafirmación de su legitimidad social. También incluyen incorporar más participación ciudadana en la gestión, la recuperación de una visión estratégica de largo plazo y que vaya más allá de la escala regional -sería beneficioso para el instituto y para el país que el ICE se integrara a la Organización Internacional de Telecomunicaciones de las Américas (OITA), una prometedora instancia de cooperación regional recientemente conformada por las empresas estatales de telecomunicaciones de Argentina, Bolivia, Brasil, Cuba, Ecuador, Paraguay, Uruguay y Venezuela- y la profundización de la alianza estratégica con el sector académico.

Para finalizar, entendemos que las perspectivas del ICE no son necesariamente sombrías. La gran movilización social del año 2000 contra el combo contradice la imagen de una sociedad despolitizada tan típica de otras socialdemocracias. Los ciudadanos de Costa Rica ya han demostrado que no son pasivos por naturaleza y que en circunstancias críticas están dispuestos a tomar las calles para defender su modelo de desarrollo solidario, del cual el ICE es la institución más emblemática. Las noticias sobre movilizaciones sociales en defensa del instituto que llegan desde San José mientras redactamos esta última frase son alentadoras. 


\section{REFERENCIAS}

Arias Molina, O., y R. Mora Chaves (2012). Energías renovables. Geotermia de baja entalpía: Experiencias exitosas y potencial en Costa Rica. Ponencia presentada al IV Congreso Nacional de Energía, 15 de febrero, San José.

Asamblea Legislativa (2010). Ley General de Electricidad. Expediente N. ${ }^{\circ}$ 17.812. La Gaceta Digital (San José), 1 de septiembre.

Bull, B. (2008). Globalización, Estado y Privatización: Proceso Politico de las Reformas de Telecomunicaciones en Centroamérica. San José: FLACSO.

Bulmer-Thomas, V. (1987). The Political Economy of Central America Since 1920. Cambdrige: Cambridge University Press.

Centro Nacional de Planificación Eléctrica (CENPE). (2009). Solicitud de Ajuste Ordinario de Tarifas Eléctricas. San José: Centro Nacional de Planificación Eléctrica-Instituto Costarricense de Electricidad.

Comisión Económica para América Latina y el Caribe (CEPAL). (2003). Evaluación de Diez Años de Reforma en la Industria Eléctrica del Istmo Centroamericano. México: Comisión Económica para América Latina y el Caribe.

. (2010). Centroamérica. Estadisticas del Subsector Eléctrico, 2010. México: Comisión Económica para América Latina y el Caribe.

Comisión para el Análisis de la Deuda Interna. (1996). Mañana Será Tarde. San José: Ministerio de Hacienda.

Coopeléctricas, Coopealfaroruiz, Coopeguanacaste, Coopesantos y Coopelesca. (2010). Proyecto de Ley: Ley General de Electricidad. San José: Coopeléctricas.

Cortés Ramos, A. (2009). Coyuntura y Politica en Costa Rica. San José: Ediciones Perro Azul.

De la Cruz, V. (1981). Las Luchas Sociales en Costa Rica: 1870-1930. San Jose: Editorial Universidad de Costa Rica.

De La Torre, T. (2010). Hacia un Nuevo Modelo Energético para Nuestro País. San José: Ministerio de Ambiente, Energía y Telecomunicaciones. 
El Financiero e INCAE (2010). Costa Rica se Apaga: País Debe Emprender Labores Urgentes para Garantizar Energía en el Futuro. San José: Centro Latinoamericano para la Competitividad y el Desarrollo SostenibleINCAE.

Fallas, C., y Alvarez, F. (1997). El ICE y la Electrificación en Costa Rica. San José: Instituto Costarricense de Electricidad.

Fernández Robles, J. A. (1985). Un Siglo de Actividad Eléctrica en Costa Rica. 1884-1984. San José: Librería e Imprenta LIL.

Frente Interno de Trabajadores del ICE (FIT-ICE). (2011). Por la Defensa de la Seguridad Eléctrica de Costa Rica y del ICE. San José: Frente Interno de Trabajadores del ICE.

Fumero Paniagua, G. (2006a). Reformas Internas en el ICE durante los Últimos 10 Años. Revista de Ciencias Sociales de la Universidad de Costa Rica, 1 (2), 81-90.

. (2006b). El Estado Solidario frente a la Globalización. Debate sobre el TLC y el ICE. San José: Zeta Servicios Gráficos.

Grosfoguel, R. (2003). Cambios Conceptuales desde la Perspectiva del Sistema Mundo: Del Cepalismo al Neoliberalismo. Nueva Sociedad, $183,151-166$

Haglund, L. (2006). Hard-pressed to Invest: The Political Economy of Public Sector Reform in Costa Rica. Revista Centroamericana de Ciencias Sociales, 1 (5), 5-46.

. (2011). Limiting Resources: Market-Led Reform and the Transformation of Public Goods. University Park: Penn State Press.

Hoffmann, B. (2007). Why Reform Fails: The "Politics of Policies" in Costa Rican Telecommunications Liberalization. Hamburgo: German Institute of Global and Area Studies / Leibniz-Institut für Globale und Regionale Studien.

International Energy Agency (IEA). (2011). World Energy Outlook 2011. Londres: International Energy Agency.

International Telecommunications Union (ITU). (2006). World Telecommunication/ICT Indicators Database. Ginebra: International Telecommunications Union. 
Jiménez Gómez, R. (2009). Análisis del Proceso de Formulación de Politicas para la Reforma del Sector Eléctrico y su Potencial Incidencia en el Marco Institucional y la Producción de Fuentes Renovables. Tesis de Doctorado, Universidad de Costa Rica, Costa Rica.

(2011). La Provisión de Electricidad como Servicio Público: la Experiencia del ICE. Ponencia presentada al Seminario Internacional Alternativas a la Privatización de los Servicios Públicos y Políticas Sociales (Transnational Institute y Municipal Services Project), 24-25 de noviembre, Montevideo.

Junta Fundadora de la Segunda República. (1949). Decreto Ley 449. Reglamento para la Creación del Instituto Costarricense de Electricidad. San José: Junta Fundadora de la Segunda Republica.

La Nación (1996). Lío por Proyectos Relacionados con ICE. Figueres Niega Pugna de Intereses. La Nación, 11 de octubre.

. (2003). Sindicatos Anuncian Huelga General a partir del Lunes. La Nación (San José), 30 de mayo.

. (2007). Editorial. Dependencia de energía térmica. La Nación (San José), 29 de enero.

(2012). Editorial. Contingencia eléctrica. La Nación (San José), 25 de febrero.

Mayorga, A. (2007). Arias Aboga porque Empresa Privada Pueda Generar Más Energía Eléctrica. La Nación (San José), 1 de mayo.

Mesa-Lago, C. (2003). Market, Socialist, and Mixed Economies: Comparative Policy and Performance. Chile, Cuba, and Costa Rica. Baltimore: The Johns Hopkins University Press.

Monge, R. (2000). La Economía Política de un Intento Fallido de Reforma en Telecomunicaciones. En R. Jiménez (Ed.), Los Restos Políticos de la Reforma Económica en Costa Rica. San José: Academia de Centramérica.

Noguera, Y. (1996. Déficit rondará el 2\%. Habrá que negociar con FMI, dice Herrero. La Nación, 15 de junio.

Organización Latinoamericana de Energía (OLADE). (2010). Energía en Cifras 2010. Quito: Organización Latinoamericana de Energía. 
Poltronieri, J. (2011). Proyecto de Investigación Estructuras de la Opinión Pública: Encuesta de Opinión Pública XXIII - 2011, Panorama Global. San José: Universidad de Costa Rica.

Rodríguez Argüello, P. (2000). Desarrollo y Regulación de los Servicios Públicos en Costa Rica. San José: Autoridad Reguladora de los Servicios Públicos de Costa Rica.

Rojas Bolaño, M. (1986). Lucha Social y Guerra Civil en Costa Rica. 19401948. San José: Editorial Alma Mater.

Rovira Mas, J. (1989). Costa Rica en los años '80. San José: Editorial Porvenir.

. (Ed.). (2001). La democracia de Costa Rica ante el Siglo XXI. San José: Universidad de Costa Rica.

Seligson, M. A. (2002). Trouble in Paradise? The Erosion of System Support in Costa Rica, 1978-1999. Comparative Politics, 37 (1), 160-185.

Shin, G.-W. y Hytrek, G. (2002). Social Conflict and Regime Formation. A Comparative Study of South Korea and Costa Rica. International Sociology, 7 (4), 459-480.

Sindicato de Ingenieros y Profesionales del ICE (SIICE). (2011). Análisis del Proyecto de Ley General de Electricidad Presentado por el Poder Ejecutivo. Expediente Número 17812. San José: Sindicato de Ingenieros y Profesionales del ICE, Racsa, Filial CNFL y Proyectos.

Sojo, A. (1984). Estado Empresario y Lucha Politica en Costa Rica. Editorial Universitaria Centroamericana.

United Nations Development Programme (UNDP). (2011). Human Development Report 2011. Sustainability and Equity: A Better Future for All. Nueva York: United Nations Development Programme.

Urcuyo, C. (2005). Reforma Política y Gobernabilidad. San José: Editorial Juricentro.

Vargas, A. (2005). La Via Costarricense: Volver Al Futuro y Reencontrar el Camino de la Prosperidad, la Equidad y la Dicha. San José: Editorial Universidad Estatal a Distancia. 
Vega Carballo, J. L. (2008). Los Arias Concentran Demasiado Poder del Pastel Nacional. Semanario Universidad, 14 de septiembre.

Ventura, V. H., Alvarado, J., Rojas, M. E. y Torijano, E. (2011). Estudio Sectorial Regional sobre Energía y Cambio Climático en Centroamérica. México, DF: Comisión Econonómica para América Latina y el Caribe.

Wilde-Ramsing, J. y Potter, B. (2006). Blazing the Green Path: Renewable Energy and State-Society Relations in Costa Rica. The Journal of Energy and Development, 32 (1), 69-92.

Wilson, B. (1994). When Social Democrats Choose Neoliberal Economic Policies: The Case of Costa Rica. Comparative Politics, 26 (2), 149-168.

(1998). Costa Rica: Politics, Economics, and Democracy. Boulder: Lynne Rienner Publishers.

Ziesing, H. J. (2012). Perspectives of World Energy and the Impacts on Energy Policy. Ponencia presentada IV Congreso Nacional de Energía, 15 de febrero, San José.

Recibido: 01-12-2012

Aceptación de la versión final: 10-04-2013 